\title{
Normalising comparative effectiveness trials as clinical practice
}

\author{
Tom Briffa ${ }^{1}$, Tanya Symons ${ }^{2}$, Nikolajs Zeps ${ }^{3}$, Nicola Straiton ${ }^{2,4^{*}} \mathbb{D}$, William Odita Tarnow-Mordi ${ }^{2}$, John Simes ${ }^{2}$, \\ Ian A. Harris ${ }^{5}$, Melinda Cruz ${ }^{2,6}$, Steven A. Webb ${ }^{7}$, Edward Litton ${ }^{8}$, Alistair Nichol ${ }^{7}$ and Christopher M. Williams ${ }^{9}$
}

\begin{abstract}
There is a lack of high-quality evidence underpinning many contemporary clinical practice guidelines embedded in the healthcare systems, leading to treatment uncertainty and practice variation in most medical disciplines. Comparative effectiveness trials (CETs) represent a diverse range of research that focuses on optimising health outcomes by comparing currently approved interventions to generate high-quality evidence to inform decision makers. Yet, despite their ability to produce real-world evidence that addresses the key priorities of patients and health systems, many implementation challenges exist within the healthcare environment.

This manuscript aims to highlight common barriers to conducting CETs and describes potential solutions to normalise their conduct as part of a learning healthcare system.
\end{abstract}

Keywords: Comparative effectiveness, Pragmatic, Trials, High-quality evidence, Clinical care, Embed

\section{Background}

Many recommendations contained in contemporary clinical practice guidelines (CPG) are not supported by high quality evidence [1]. In Australia, almost three in ten evidence statements covering 748 graded recommendations from ten CPGs are low quality or consensusbased. Less than half are based on high quality evidence derived from randomised controlled trials (RCTs) or systematic review of these trials. Further afield, the picture is even more concerning. In many medical specialities, in North America and Europe, less than 20\% of recommendations are supported by high quality evidence [1$3]$ and in specialities such as cardiology, little has changed in the last 10 years [3]. As a result, clinicians, patients, health systems and the public are unable to determine the comparative safety and efficacy of accepted treatments [4]. Clearly, more progressive

\footnotetext{
* Correspondence: nicola.straiton@clinicaltrialsalliance.org.au

${ }^{2}$ University of Sydney, Sydney, New South Wales, Australia

${ }^{4}$ Australian Clinical Trials Alliance, Suite 1, Level 2, 24 Albert Road, Melbourne, VIC 3205, Australia

Full list of author information is available at the end of the article
}

approaches to evidence generation are needed to expand and strengthen the quality of recommendations in CPGs.

Comparative effectiveness trials (CETs) address this conundrum by randomising participants to usual care alternatives in order to generate unbiased, high-quality evidence of the relative effectiveness of existing treatments [5]. Their purpose is to assist clinicians, healthcare providers, policy makers and patients make informed decisions that improve health care at both the individual and population level. CETs often adopt pragmatic designs, and their key features are illustrated in Fig. 1.

As the treatment options investigated are widely used in practice, the additional risk to patients is low. Furthermore, public opinion polls repeatedly confirm that patients want their health systems to be 'research active' so that they are better informed about the benefits and risks of different treatments [4-6]. It seems likely, therefore, that working to normalise the conduct of CETs in clinical practice will help strengthen the clinician-patient relationship, especially when health systems are

(c) The Author(s). 2021 Open Access This article is licensed under a Creative Commons Attribution 4.0 International License, which permits use, sharing, adaptation, distribution and reproduction in any medium or format, as long as you give appropriate credit to the original author(s) and the source, provide a link to the Creative Commons licence, and indicate if changes were made. The images or other third party material in this article are included in the article's Creative Commons licence, unless indicated otherwise in a credit line to the material. If material is not included in the article's Creative Commons licence and your intended use is not permitted by statutory regulation or exceeds the permitted use, you will need to obtain permission directly from the copyright holder. To view a copy of this licence, visit http://creativecommons.org/licenses/by/4.0/ The Creative Commons Public Domain Dedication waiver (http://creativecommons.org/publicdomain/zero/1.0/) applies to the data made available in this article, unless otherwise stated in a credit line to the data. 


\begin{tabular}{ll}
\hline & \multicolumn{1}{c}{ Commonly cited characteristics of pragmatic trials } \\
\hline Purpose: & To inform decision-makers \\
\hline Study Design: & Individual-level RCT, Cluster Randomised, Step Wedge, Cohort Multiple-Randomised \\
\hline Study Population: & Heterogeneous (minimal eligibility criteria) \\
\hline Setting: & Commonly where patients already receive their usual clinical care \\
\hline Endpoints: & Important to patients, typically encountered in clinical care \\
\hline Follow-up: & Aligned with standard care \\
\hline Data & Existing electronic sources (electronic medical record) \\
\hline Monitoring: & Minimal \\
\hline Cost & Low \\
\hline
\end{tabular}

Fig. 1 Key features of pragmatic comparative effectiveness trials

encouraged to partner with consumers to create learning healthcare systems (LHS), where the conduct of CETs and other high-quality research is routine, embedded and continuous [7]. The concept of an LHS was first introduced by the Institute of Medicine [8] to combat the unsustainable growth in US healthcare spending, but despite CETs being considered an essential component of an LHS, their embedding into routine practice has proven challenging. This perspective illustrates these barriers and summarises commentary on the mechanisms that could support their embedding into the health system.

Many factors have stymied attempts to integrate CETs into clinical care. Indeed, the characteristics that support their pragmatism can also hamper their conduct. For example, to preserve external validity, CETs necessarily avoid certain design features required for high internal validity, (blinding, strict inclusion criteria and a highly controlled setting) [9]. However, the large sample sizes required to account for this make some trials prohibitively expensive. In response trialists have dispensed with the costly, parallel infrastructure that is set up for each trial and instead, collect data straight from medical records and utilise front-line clinicians to undertake study activities such as informed consent. But front-line clinicians can be reticent to involve themselves in trials, partly because there are few financial (or other) incentives, and partly because they fear that such involvement may overly disrupt their clinical workflows. Very few, therefore, recommend trial participation to their patients leading to a lack of trial awareness amongst the population.

Health system leaders too are reluctant to allocate resources to support trial activity, perhaps because the research agenda has historically been driven by academics and the trials conducted within their institutions have not always been in line with health system priorities.
One of the most significant barriers to the adoption of CETs for contemporary evidence generation is the absence of proportionate approaches to trial governance.

Currently, the policy framework and governance arrangements applied to CETs are largely identical to those for trials involving novel interventions. For example, some CETs compare interventions in which verbal consent to treatment would have been obtained outside the trial setting. Yet, when formally comparing two standard treatments, lengthy, legalistic consent forms are mandated, despite growing evidence that patients prefer simpler ways to be informed about such research that do not overinflate the perception of risk [10, 11]. Therefore, a range of consent models that reflect the extent to which a trial departs from usual care seem appropriate. Some countries, including Australia, endorse a proportionate approach to trial consent [9] but uptake is still low due to fear of censure.

\section{Solutions to normalise the conduct of CETs}

Efforts to develop, design and conduct CETs will continue to require creative approaches to overcome common challenges. Table 1 describes commentary on these challenges and possible solutions so enable the embedding of CETs into the health system.

\section{Conclusion}

The failure of health systems to ground everyday treatments in sound science impacts the quality of care provided to patients and contributes to health system waste. Conducting CETs that provide robust and generalisable evidence to guide practice is a public good. Importantly, patients recognise this and consistently confirm that they want their health systems to be research-active. 
Table 1 Solutions for embedding CETs

\section{Barriers to embedding}

The lack of a culture of continuous improvement where knowledge creation is explicitly recognised as a core activity of the health system

Failure to apply risk-proportionate governance practices to CET

Difficulties designing and conducting large, efficient CETs

Limited engagement from patients and the public as active partners in advancing the delivery of care

\section{Possible solutions}

- Introduce health system accreditation acknowledging centres of excellence based on indicators of research activities.

- Incentivise Chief Executive Officers and board members to advance the role of research in their organisations.

- Improve health system leader buy-in by more closely aligning research activity with health system priorities.

- Improve stakeholder buy-in by structuring learning to focus on the outcomes of care delivery, increasing return on investment, and decreasing costs.

- Engage all stakeholders to create widespread awareness of the pivotal role clinical research plays in the generation of high-quality evidence and improved health outcomes.

- Restructure workflow to incorporate research activity with protected time and provide incentives for clinicians who contribute to research-driven clinical improvements.

- Support studies conducted by investigator networks to address real-world evidence gaps.

- Ensure proportionate approaches to trial ethics and governance approval that expedite study approval when trial risks are low

- Utilise existing flexibilities in trial regulation to improve trial conduct (e.g. the use of flexible, patient-supported approaches to informed consent).

- Ensure governance arrangements for CETs balance a trial's risk against the risks posed by current, unresearched care.

- Ensure that patients are involved in trial governance decisions and the design of research ethics and regulatory systems.

- Harmonise requirements for trial conduct to facilitate international collaboration.

- Ensure trial networks collaborate with consumers and frontline clinicians to share expertise and knowledge and to drive more efficient trial practices.

- Utilise novel trial designs that minimise disruption to clinical workflows.

- Utilise trial platforms to create a coordinated approach to evidence generation

- Incorporate implementation science strategies into CETs to facilitate uptake of evidence-based practice.

- A cost-effectiveness analysis into, or alongside trials.

- Introduce health system accreditation for 'partnering with consumers' to develop clinical trials operations so that research policies and practices reflect the needs and preferences reflect the needs and preferences of service users.

- Co-design with patients a communication strategy to widely broadcast research as a core activity of the health system and that data and tissue is used to improve care within a framework that safeguards privacy and confidentiality.

- Assist/enable patients to prioritise research questions so that the questions investigated, and the outcomes chosen are those most important to them. - Involve patients in the design of research so that it is conducted in ways that are sensitive to participants' needs (e.g. by minimising the burden of participation).

Adapted from Symons et al. 2021. Making the move to a learning healthcare system: has the pandemic brought us one step closer? (https://doi.org/10.1071/AH21076)

Although some progress has been made, few healthcare organisations have successfully transitioned into LHSs that conduct trials as an integral part of the delivery of high-quality care. Despite progress in areas such as trial design, lingering challenges remain, not least, the need to develop risk-proportionate regulatory and governance frameworks that facilitate the conduct of large, pragmatic CET by them being less expensive and cumbersome to conduct.

Implementing solutions that address the factors that currently prevent the embedding of CETs as a core activity of the health system will require disruptive change, but without such change, the widespread use of low-value or suboptimal treatments will remain unchecked.

\section{Acknowledgements}

We acknowledge the Australian Clinical Trials Alliance (ACTA) for their support of the investigator-led clinical trials sector and activities to further embed clinical trials into routine care.

\section{Authors' contributions}

TB and TS led the writing group on normalising comparative effectiveness trials as clinical practice. CW, NZ, and NS all co-wrote the perspective; WOT- 
$M, J S, I A H, M C, S A W, E L$, and AN all contributed to writing the perspective. All authors conceived, read, and approved the final perspective. All authors read and approved the final manuscript.

\section{Authors' information}

Correspondence to Professor Tom Briffa tom.briffa@uwa.edu.au.

\section{Funding}

This project received grant funding from the Australian Government.

\section{Availability of data and materials}

Not applicable.

\section{Declarations}

Ethics approval and consent to participate

Not applicable.

\section{Consent for publication}

Not applicable.

\section{Competing interests}

TS provides clinical research consulting services in Australia and the UK however, no organisation controlled or influenced the development of this manuscript. The other authors have no competing interests.

\section{Author details}

${ }^{1}$ University of Western Australia, Perth, Western Australia, Australia. ${ }^{2}$ University of Sydney, Sydney, New South Wales, Australia. ${ }^{3}$ Epworth HealthCare,

Richmond, Victoria, Australia. ${ }^{4}$ Australian Clinical Trials Alliance, Suite 1, Level 2, 24 Albert Road, Melbourne, VIC 3205, Australia. ${ }^{5}$ Ingham Institute, Liverpool, New South Wales, Australia. 'University of New South Wales, Sydney, New South Wales, Australia. ${ }^{7}$ Monash University, Melbourne, Victoria, Australia. ${ }^{8}$ Fiona Stanley Hospital, Murdoch, Western Australia, Australia.

${ }^{9}$ University of Newcastle, Callaghan, New South Wales, Australia.

Received: 13 May 2021 Accepted: 24 August 2021

Published online: 15 September 2021

\section{References}

1. Australian Commission on Safety and Quality in Healthcare. The National Clinical Trials Governance Framework and User Guide for Health Service Organisations Conducting Clinical Trials 2020. Available at https://www.sa fetyandquality.gov.au/publications-and-resources/resource-library/nationalclinical-trials-governance-framework-and-user-guide. Accessed 5 Aug 2021.

2. Institute of Medicine. Integrating research and practice: health system leaders working toward high-value care: workshop summary. Washington DC: The National Academies Press; 2015.

3. Califf RM, Robb MA, Bindman AB, et al. Transforming evidence generation to support health and health care decisions. N Engl J Med. 2016;375:24.

4. Australian Clinical Trials Alliance. International Best Practice Towards a Learning Healthcare System: a scoping activity to map international approaches to embed clinical trials into the healthcare system. 2018. Available at https://clinicaltrialsalliance.org.au. Accessed 22 July 2021

5. Psek W, Davis FD, Gerrity G, Stametz R, Bailey-Davis L, Henninger D, et al. Leadership perspectives on operationalizing the learning health care system in an integrated delivery system. eGEMS. 2016;4(3):6. https://doi.org/10.13 063/2327-9214.1233.

6. Psek WA, Stametz RA, Bailey-Davis LD, et al. Operationalizing the learning health care system in an integrated delivery system. eGEMs (Generating Evidence \& Methods to improve patient outcomes). 2015;3(1):6.

7. Gelijns AC, Gabriel SE. Looking beyond translation — integrating clinical research with medical practice. N Engl J Med. 2012;366(18):1659-61. https:// doi.org/10.1056/NEJMp1201850.

8. Symons T, Webb S, Zalcberg J. Putting the "good" into Good Clinical Practice. Med J Aus. 2021;214(2):62-65.e1.

9. Webster M, Stewart R, Aagaard N, McArthur C. The learning health system: trial design and participant consent in comparative effectiveness research. Eur Heart J. 2019;40(15):1236-40. https://doi.org/10.1093/eurheartj/ehy235.
10. Ramsberg J, Platt R. Opportunities and barriers for pragmatic embedded trials: triumphs and tribulations. Learn Health Syst. 2018;2(1):e10044. https:// doi.org/10.1002//rh2.10044.

11. Angus DC. Optimizing the trade-off between learning and doing in a pandemic. JAMA. 2020;323(19):1895-6. https://doi.org/10.1001/jama.2020.4 984.

\section{Publisher's Note}

Springer Nature remains neutral with regard to jurisdictional claims in published maps and institutional affiliations.
Ready to submit your research? Choose BMC and benefit from:

- fast, convenient online submission

- thorough peer review by experienced researchers in your field

- rapid publication on acceptance

- support for research data, including large and complex data types

- gold Open Access which fosters wider collaboration and increased citations

- maximum visibility for your research: over $100 \mathrm{M}$ website views per year

At $\mathrm{BMC}$, research is always in progress.

Learn more biomedcentral.com/submissions 